\title{
SISTEM INFORMASI PENJUALAN MOBIL BEKAS BERBASIS WEB PADA PT. UMI FORD BANJARMASIN
}

\author{
Dwi Agung Wibowo \\ Fakultas Teknologi Informasi \\ Universitas Islam Kalimantan Muhammad Arsyad Al Banjari Banjarmasin \\ email: agungfti@gmail.com
}

\begin{abstract}
ABSTRAK
Pada Kepegawaian yang memiliki tugas menyelenggarakan data karyawan, data barang masuk dan keluar, pemesanan mobil, data customer, serta gaji karyawan. Dalam proses yang berjalan sekarang berupa data yang menyangkut penjualan mobil bekas masih dilakukan secara manual belum terkomputerisasi dan terorganisasi.Permasalahan yang sering dihadapi pada PT UMI Ford Banjarmasinkhususnya untuk sales consultan adalah proses penjualan mobil bekas karena masih dilakukan secara manual dan masih dilakukan secara perorangan belum ada devisi yang menangani secara khusus. Karena dilakukan secara perorangan terkadang memakan waktu yang cukup lama, sehingga mempengaruhi pada penjualan mobil barunya.Dengan di buatnya Sistem Informasi Penjualan Mobil Bekas Berbasis Webtersebut dapat memaksimalkan permasalahan yang sebelumnya masih manual sekarang sudah terkomputerisasi dan dapat menyelesaikan permasalahan tersebut .
\end{abstract}

Keywords : Sistem Informasi Penjualan Mobil Bekas

\section{PENDAHULUAN a.Latar Belakang Masalah}

Dewasa ini perkembangan bidang teknologi informasi sangat pesat, oleh karena itu sudah banyak pula perusahaan, industri, pertokoan, dan badan usaha lain yang menggunakan sistem informasi untuk meningkatkan usahanya. PT. United Mobil International, khususnya Ford Banjarmasin merupakan Dealer Mobil yang bergerak di bidang penjualan mobil baru. Dalam perjalanannya tidak jarang menemui konsumen yang ingin enjual mobil lamanya dan ditukar dengan mobil baru, sehingga itu merupakan salah satu kendala dalam melakukan transaksi mobil baru.

Dalam kegiatan perusahaan untuk meningkatkan penjualan sudah melakukan input data konsumen dan penjualan dengan cara online, hanya saja itu terpaku pada mobil baru, terkadang salesnya sendiri yang harus mencari pembeli untuk mobil bekasnya. Berangkat dari permasalahan itulah maka di ambilah penelitian dengan judul "Sistem Informasi Penjualan Mobil Bekas Berbasis
Web pada PT. UMI Ford Banjarmasin "untuk mempermudah team sales dalam memasarkan produk mobil bekas yang di perjual belikan pada PT. UMI, Ford Banjarmasin.

\section{b.Rumusan Masalah}

Berdasarkan masalah yang dijelaskan maka perumusan masalah adalah Bagaimana membuat suatu sistem informasi penjualan mobil bekas berbasis web untuk mempermudah mempromosikan penjualan mobil bekas pada PT. UMI, Ford Banjarmasin.

\section{c.Tujuan Penelitian}

Tujuan penelitian ini adalah merancang suatu sistem informasi penjualan mobil bekas berbasis web yang dapat digunakan untuk sarana promosi, yang nantinya bisa menjadi bahan pertimbangan bagi calon pembeli.

\section{d.Manfaat penelitian}


Dengan dirancangnya sistem informasi ini diharapkan dapat memberikan manfaat sebagai berikut :

1. Bagi calon pembeli, memberikan gambaran secara umum tentang nilai mobil yang akan mereka beli.

2. Bagi team sales, memberikan gambaran secara umum mengenai selera dari calon pembeli, dan sebagai media lain selain koran atau brosur dalam mengiklankan mobil yang akan mereka jual.

3. Bagi perusahaan secara umum bagaimana agar transaksi berjalan tanpa ada hambatan yang berarti, sehingga dapat meningkatkan pada penjualan mobil baru.

\section{METODE PENELITIAN}

Tujuan penjualan adalah pernyataan penjualan yang dinyatakan dalam volume penjualan.Tujuan ini dapat dipecah berdasarkan penentuan apakah volume yang ingin dicapai itu berdasarkan perwilayah operasional atau perorangan dalam wilayah operasi.

\section{Penjualan}

Penjualan merupakan suatu transaksi yang dilakukan oleh dua belah pihak atau lebih dengan menggunakan alat pembayaran yang sah, dengan penjualan juga merupakan salah satu sumber pendapatan seseorang atau perusahaan yang melakukan transaksi jual dan beli, dalam suatu perusahaan apabila semakin besar penjualan maka akan semakin besar pula pendapatan yang diperoleh.

\section{Network}

Network adalah jaringan dari system komunikasi data yang melibatkan sebuah atau lebih system computer yang dihubungkan dengan jalur transmisi alat komunukasi membentuk satu sistem.Dengan network, computer yang satu dapat menggunakan data dikomputer lain,dapat nmencetak laporan diprinter lain,dapat memberikan berita kekomputer lain walaupun berlainan area.Network merupakan cara yang sangat berguna untuk mengintegrasikan system informasi dan menyalurkan arus informasi dari satuarea kearea lainnya.

\section{Pengertian Internet}

Internet (Interconnected Netwoek) merupakan jaringan computer yang terdiri dari ribuan jaringan computer independen yang di hubungkan satu dengan yang lainnya. Secara etimologis, internet berasal dari bahasa inggris yakni inter berarti antar dan net berarti jaringan sehingga dapat di artikan hubungan antar jaringan

Jaringan computer terdiri dari lembaga pendidikan, pemerintahan, militer, organisasi dan bisinis dan organisasi lainnya.Internet atau nama pendeknyaNet merupakan jaringan computer yang tersebar didunia.Sampai saat ini internet sudah menghubungkan lebih dari 100000 jaringan komputer dengan pemakai lebihdari 100juta orang.

\section{Pengenalan MySQL}

$M y S Q L$ dikembangkan oleh sebuah perusahaan Swedia yang pada saat itu bernama TcX. Data Konsult AB,dan pada akhirnya berubah nama menjadi MySQLAB.Sekitar tahun1994-1995,TcX membuat database MySQL untuk mengembangkan aplikasi web bagi klien-nya. TcX merupakan perusahaan pengembang software dan konsultan databaseMichaelWidenius atau disebut"Monty" adalah pengembang satusatunya diTcX. Dengan berlandaskan pada aplikasi UNIREG dan ISAM yang dibuat sendiri,dia memutuskan untuk mencari antar muka $S Q L$ yang sangat tepat untuk ditempelkan di atasnya. Awalnya dia menggunakan $m S Q L$ singkatan dari mini SQL(Structure Query Language).Dia beranggapan bahwa $m S Q L$ merupakan satusatunya kode database open source yang tersediadan cukup sederhana saat itu.Namun setelah iya melakukan uji coba,ternyata $m S Q L$ tidakcukup cepat dan fleksibel.Danpada versi pertama $m S Q L$ tidak memiliki indeks. Setelah itu,dia menghubungi DavidHughesse bagai pembuat $\mathrm{mSQL}$, namun karena David tengah sibuk dalam mengembangkan versi2 $\mathrm{mSQL}$, maka Monty memutuskan untuk membuatsendiri mesin $S Q L$ yang antar muka miripdenagn $S Q L$, namun memiliki kemampuan yang lebih sesuai kebutuhkan, sehingga lahirlah $M y S Q L$

Terdapat perbedaan pendapat seputar asal muasal namaMySQLitu sendiri,ada yang mengatakann bahwa nama $M y S Q L$ diambil 
dari namadepan dan belakang sebutan dari MichaelWidenius,yaituMonty. Ada pulayang mengatakan kataMy itusen diri diambil dari nama putrid Monty, yang bernamaMy. Jika kita amati sourcecode MySQL itu sendiri, prefix My memang sudah menjadi prefiksumum apabila seseorang ingin membuat kode kustom sendiri.

\section{Tinjauan Singkat PT. UMI Ford Banjarmasin}

PT. United Mobil International, Ford Banjarmasin berdiri di Kota Banjarmasin pada Tahun 2003 yang beralamat di jalan Ahmad Yani km 6 Banjarmasin selatan, hingga sekarang dengan segala perkembangannya. Awal mula berdiri Ford Banjarmasin hanya menggunakan bangunan Ruko biasa dan unit mobil yang di tawarkan masih hanya untuk jenis comersil atau biasa disebut dengan mobil angkutan ( usaha ), akan tetapi dengan segala kemajuannya dan kepercayaan masyarakat pada kwalitas dari mobil ford, maka tidak salah apabila PT. UMI, Ford Banjarmasin untuk menambah varian-varian baru, sehingga dapat mencakup semua kalangan, tidak hanya untuk usaha saja tapi untuk keluarga pun juga ada.

PT. UMI Ford Banjarmasin bergerak dalam bidang penjualan mobil baru dan sebagai dealer satu-satu untuk Kalimantan selatan yang berhak untuk memasarkan mobil dengan Merk Ford.Dalam pemasaran mobil baru sudah mengikuti perkembangan zaman, promosi yang di lakuan dari media elektronik, media cetak dan juga sales consultan.

\section{Analisa Sistem Berjalan}

Analisa sistem yang dilakukan pada PT. UMI, Ford Banjarmasin untuk mengetahui sejauh mana sistem dapat dikembangkan dan diterapkan yang tentunya tidak terlepas dari keinginan untuk memperoleh hasil yang maksimal. Alasan yang mendorong untuk mengembangkan sistem informasi penjualan mobil bekas berbasis web adalah sebagai berikut :

1. Belum memanfaatkan teknologi informasi berbasis web, sebagai daya saing kompetitif bagi bidang usahanaya.
2. Belum dilihat sebagai suatu peluang bahwa trend teknologi informasi berbasis web dapat digunakan untuk interaksi antara bidang usaha penjual dengan konsumen.

\section{Kelemahan Sistem Berjalan}

Untuk kelemahan yang terdapat pada sistem yang sudah ada maka dapat ditarik kesimpulan bahwa tidak terkoordinasi dalam melakukan penjualan mobil bekas, sehingga agak kesusahan dalam mencari pembeli mobil bekas. Pada akhirnya berdampak pada target yang ada akan susah untuk di capai.

\section{Sasaran Sistem yang di kembangkan}

Sebelum sistem dikembangkan perlu adanya perumusan dan perencanaan yang jelas karena menyangkut berbagai sistem organisasi, sehingga dapat ditentukan sasaran dari sistem yang dikembangkan.

\section{Identifikasi kebutuhan Hardware dan Software}

Adapun perangkat keras ( Hardware ) yang dibutuhkan dalam sistem adalah sebagai berikut :

- Komputer / laptop

- Printer

- Wifi

- UPS

Sedangkan untuk perangkat lunak ( Software ) yang digunakan adalah sebagai berikut :

- Sistem Operasi

- Sistem Program

- Sistem Pemrograman database

- Sistem pemrograman web server

\section{Identifikasi Kebutuhan Data dan Informasi}

Identifikasi kebutuhan data dan informasi ini dapat di gunakan untuk mempermudah dalam merancang sistem yang di kembangkan. Kemampuan, syarat atau kriteria yang harus ada atau dipenuhi oleh sistem informasi, sehingga hasil yang bisa 
diperoleh dengan adanya Analisis dan Perancangan sistem informasi ini berupa kemudahan dalam menentukan pengolahan data dan menampilkan laporan-laporan yang diperlukan ( Output ) dapat diwujudkan, sehingga kebutuhan akan Analisis dan perancangan sistem informasi pada PT. UMI Ford Banjarmasin menjadi lebih mudah dan pelayanan terhadap konsumen akan lebih baik.

\section{Flowchart Menu Utama}

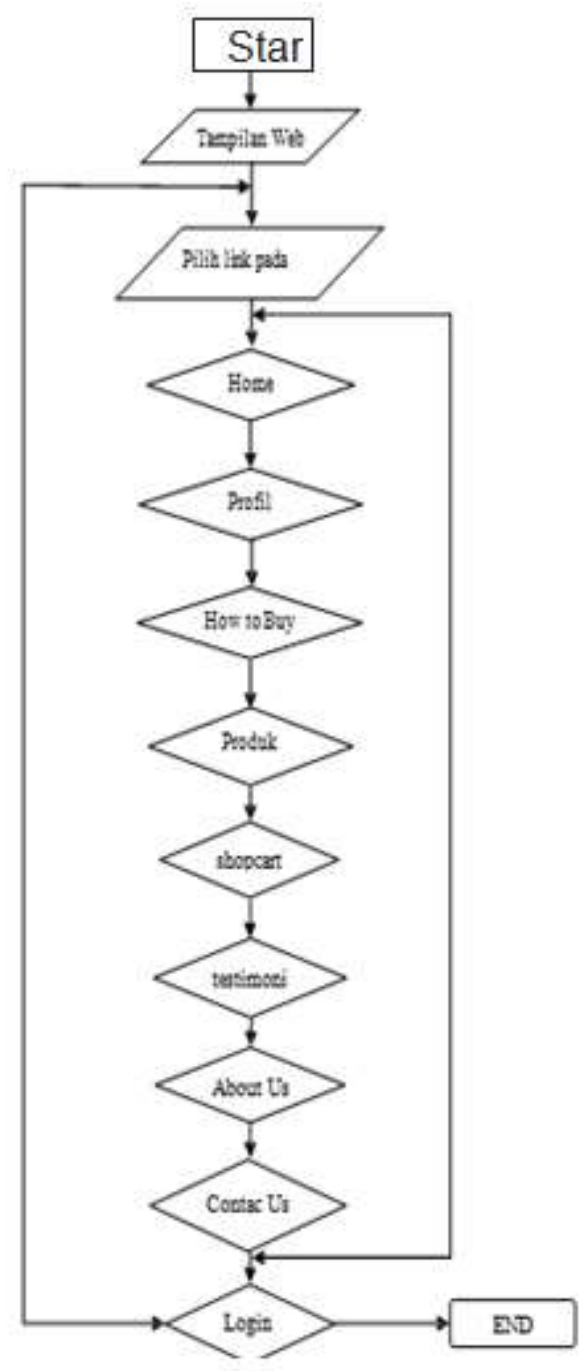

Gambar 1.Flow Chart.

\section{HASIL DAN PEMBAHASAN}

Spesifikasi Sistem

Setelah dianalisis dan dirancang secara rinci dan teknologi telah diseleksi dan dipilih. Tiba saatnya,system untuk diimplementasikan.Implementasi sistem adalah langkah- langkah atau prosedur yang dilakukan dalam menyelesaikan desain system yang telah disetujui.

\section{Pengujian di Browser}

Setalah menginstal AppServ,maka aplikasi web telah dapat diujikan dikomputer lokal. Adapun caranya adalah sebagai berikut

1. Letakkanfile-file yang membangun web kedalam suatu folder,dalam hal ini penulis membuat nama foldernya"mobil"dan diletakkan didalam folder www

2. Buka browser Google Chrome atau Mozilla Firefox

3. Pada kotak URL ketikkan http://localhost/mobil/. Tampilannya seperti gambar dibawah ini

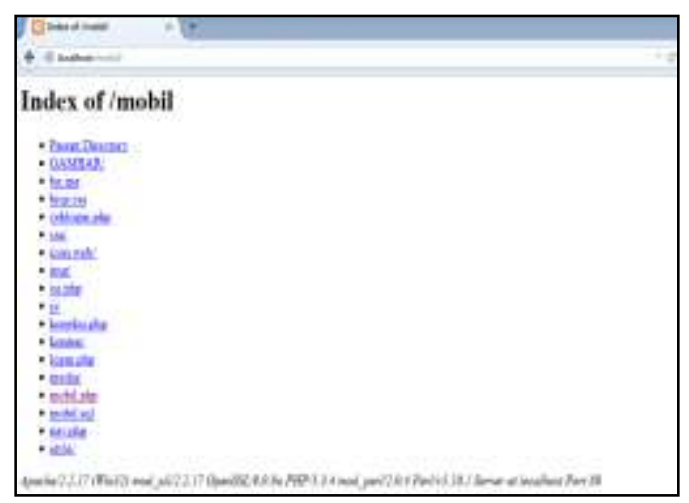

Gambar 2.Pengujian browser
Menu Utama terdapat menu login untuk admin seperti pada gambar dibawah

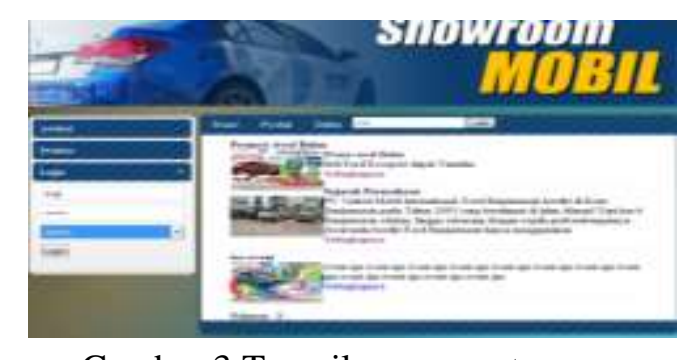

Gambar 3.Tampilan menu utama

\section{Form login}


Menu login di gunakan untuk masuk user yang telah mendaftar dalam program ini, agar lebih mempermudah dalam mendapatkan informasi yang di butuhkan.Seperti pada contoh gambar di bawah ini.

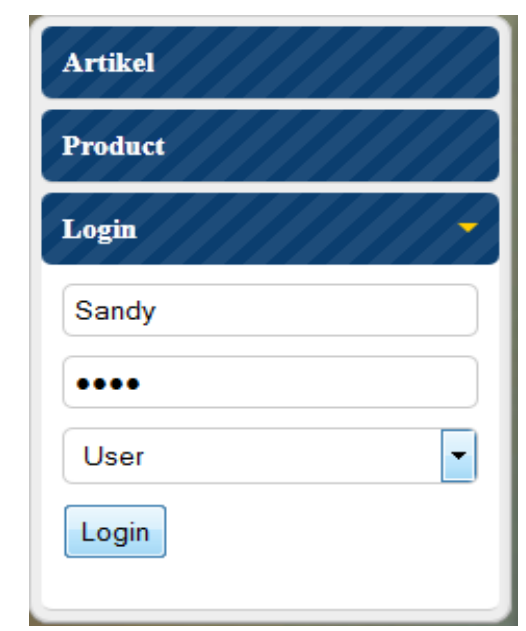

Gambar 4.Form login merupakan bab terakhir dari penelitian ini,dapat ditarik kesimpulan yakni sebagai berikut :

1. Aplikasi berbasis webdapat menjadi alternative pilihan sebagian besar masyarakat yang ingin mencari barang ataupun informasi yang sebelumnya menghabiskan waktu, tenaga, dan uang

2. Padaperancangane-commerce ini merupakan salah satu sarana untuk mendapatkan informasi online yang biasa diakses oleh siapasaja

3. Websitee-commerce ini memberikan informasi yang berkaitan dengan penjualan komputer dan aksesorisnya sesuai kebutuhan masyarakat dan pasar penjualan sekarang dan harga yang disarankan

4. Penyajian informasi yang baik dapat dilakukan dengan meng-update isi dari situs tersebut secaraberkaladan sesuai dengan perkembangan zaman sekarang

5. Perancangan websiteE-Commerce ini dibuat dengan software dreamweaver 8.0 dan pemrograman $P H P$, serta database MySQL

\section{Kesimpulan}

Berdasarkan pembahasan padababbab sebelumnya,maka pada bab ini yang

\section{REFRENSI}

Jurnal Ilmiah ”Technologia”
S. Zhang, M. Lei, Y. Dong, and W. He, "Adaptive neural network control of coordinated robotic manipulators with output constraint," IET Control Theory Appl., vol. 10, no. 17, pp. 2271-2278, 2016.

F. D. Using, S. C. Test, and A. N. Networks, "Failure Diagnosis Using the State Chisquare Test," no. 3, pp. 3279-3283.

P.-C. Chang, C.-H. Liu, C.-Y. Fan, and H.-C. Chang, "Data Clustering and Fuzzy Neural Network for Sales Forecasting in Printed Circuit Board Industry," 2007 IEEE Symp. 
Comput. Intell. Data Min., no. Cidm, pp. 107-113, 2007.

D. Dovžan, V. Logar, and I. Škrjanc, "Solving the sales prediction problem with fuzzy evolving methods," IEEE Int. Conf. Fuzzy Syst., pp. 10-15, 2012.

M. Program, S. Teknik, U. Maritim, R. Ali, and K. Kunci, "JARINGAN SYARAF TIRUAN BACKPROPAGATION ( Study Kasus : PDAM TIRTA KEPRI ) Ilham Aryudha Perdana," pp. 1-12, 2016.

P. Linda, M. Situmorang, and G. Tarigan, "Peramalan Penjualan Produksi Teh 2014 Dengan Metode Arima Box-Jenkins," vol. 02, no. 03, pp. 253-266, 2014.

J. T. Informasi, P. Teknik, I. Universitas, and D. Nuswantoro, "Prediksi Penjualan Air Minum Dalam Kemasan Menggunakan Jaringan Syaraf Tiruan Resilient," vol. 10, pp. 186-210, 2014.

V. N. Nore, "PERANCANGAN SISTEM INFORMASI PENJUALAN DAN PEMESANAN PRODUK BERBASIS WEB (Studi Kasus di CV. Richness Development Bandung)," pp. 1-11, 2013. 